\section{The ocular pulse}

SIR, - The important editorial on the ocular pulse,' highlights the observations of the retinal arterial pulsations noted by early ophthalmologists. It was Thiel $^{2}$ who first attempted to quantify the recording of the transmitted pulsations which had become known as the tonometric sign as early as 1879 . Priestley Smith $^{3}$ had clearly described the spontaneous vascular pulsations observed during tonometry. This was reinforced by the observations of Schiøtz and became an important observation for those undertaking tonometry up to the time of the applanation method.

The earliest precise recording of the ocular pulse was that of Thiel in $1928 .^{2}$ Subsequently Maurice 4 used a recording tonometer, to be followed by Castren and Lavikanen,' who adapted a Muller electrotonometer. Following the work of Suzuki a number of groups developed a system of recording the ocular pulse using a fluid filled suction cup system. The piezoelectric system of Bynke ${ }^{7}$ seems to be the least 'invasive' and most precise. The methods of Walker et $\mathrm{ll}^{8}$ and Perkins ${ }^{9}$ were later developments. In spite of the variety of approaches the amplitude and variation in pulse pressures correlate quite closely. Both in time and form the pulse wave does not correspond with a typical arterial pulsation. It lacks the dicrotic notch which is the characteristic of an arterial pulse, and when placed in time sequence in relation to the $R$-wave of the ECG, or the Doppler pulse wave recruited from an adjacent orbital vessel, for example, the supratrochlear vessel, its time relationship is closer to the middle of diastole. The only report which demonstrates a dicrotic notch is that of Barnes and co-workers, ${ }^{10}$ who applied the pulse sensor, externally, through the lids, and it is believed that this was recording ophthalmic artery pressure pulsations and not an ocular pulse.

While evidence to link the ocular pulse amplitude to either $\mathrm{C}$ or $\mathrm{PO} / \mathrm{C}$ is lacking, there is a significant amount of evidence from all studies that it has a direct relationship with levels of ipsilateral carotid perfusion. The consequence of this is to question the role of a topical $\beta$-blocker which does not contain intrinsic sympathomimetic activity (ISA).

\section{J MARMION 73 Pembroke Road, Clifton, Bristol BS8 3DW}

1 Hitchings $\mathrm{R}$. The ocular pulse [Editorial]. $\mathrm{Br} \mathcal{F}$ Ophthalmol 1991; 75: 85.

2 Thiel R. Haaornhautpulsation, Blutdruck und Augendruck. (Nach gemeinsamen Versuchen mit Reg. Rat. Dr Carl Muller (Phys Techn Reichsanstalt Berlin) und Oberingenieur Dr Wilhelm Muller (Berlin). Zentrabl Ges Ophthalmol 1928; 20: 174.

3 Smith P. Glaucoma: its causes, symptoms, patholog and treatment. London: Churchill, 1879: 23.

4 Maurice WM. A recording tonometer. $\mathrm{Br} f$ Ophthlamol 1958; 42: 321 .

5 Castren JA, Lavikanen P. A new method of diagnosing carotid disease. Acta Ophthalmol $(K b h)$ 1963; 42: 219-23.

6 Suzuki I. Corneal pulsation and corneal pulse waves. Fpn f Ophthalmol 1962; 6: 190-4.

7 Bynke HG. Influence of intraocular pressure on the amplitude of the corneal pulse. A study on man and rabbits. Acta Ophthalmol (Kbh) 1968 46: $1135-45$.

8 Walker RE, Compton GA, Langham ME. Pneumatic applanation tonometer studies IV Analysis of pulsatile response. Exp Eye Res 1975 20: 245-53.

9 Perkins ES. The ocular pulse and intraocular pressure as a screening test for carotid artery pressure as a screening test for carotid ar
stenosis. Br $\mathscr{f}$ Ophthalmol 1985; 69: 676-80.

10 Barnes RA, Martin GE, Montgomery PS Ophthalmic plethysmography technique and Ophthalmic plethysmography technique
potential. Dis Nerv Syst 1967; 28: 293-7.

\section{BOOK REVIEWS}

Aesthetic Surgery of the Eyelids. By Raul Loeb. Pp 155. Dm 360.00. Springer-Verlag: Heidelberg, 1989.

This book is written by a professor of plastic surgery who specialised in eyelid surgery. It is of interest to the ophthalmologist, as it minutely examines the normal appearance of the eyelids and the anatomical reasons for variation in this normal appearance as well as the pathophysiological changes which occu with age. The ophthalmologist usually concentrates on the functional abnormalities of the eyelids and often does not seek to differentiate the nuances of minor changes in apperarance which can be of great cosmetic significance.

There are chapters on anatomical considerations discussing the variations in bulges in the eyelids; scleral show, which is subdivided into constitutional, developmental, endocrine, and iatrogenic causes; the treatment of excess skin, fat, muscle, and bone; the treatment of depressions, complementary surgeries, and ectropions, and other complications. The author's concepts of recognising depressions in the eyelids and of supplementing deficient tissue with fat grafting or mobilisation are especially interesting. He does not set out to give a standard technical description of how to do a particular operation but rather tries to make the reader aware of the human body's individual variations and how techniques need to be modified to take account of these variation and to avoid complications. All the chapters are copiously illustrated with excellent, clear diagrams and clinical photographs, and there is an extensive bibliography and additional reading section.

Although few ophthalmologists will wish to perform all the procedures described in this book, it is valuable for showing what possibilities exist in cosmetic surgery round the eyelids.

J R O COLLIN

Manual of Fundus Fluorescein Angiography. By Amresh Chopdar. (Pp 134; £55.) Butterworth: Guildford, Surrey. 1989.

This book is based on a successful course for ophthalmologists which the author has been running on an annual basis at the East Surrey Hospital. It is divided into 11 chapters and also contains a section for further reading and an index. The first three chapters deal with the basics of angiography and both normal and abnormal fluorescence. The remaining chapters describe the appearances in the more common retinal disorders.

The strength of the book lies in the very high quality of the photographs. Each disease described has a good representative colour illustration with first class clear fluorescein angiograms. Throughout the book there is hardly a plate which is not of excellent standard.

Unfortunately the book is somewhat let down by the quality of the text, not so much in terms of accuracy as of brevity. For instance, topics such as the side effects of angiography are touched on only briefly, and there is no description of their management. No mention is made of stereo photography, which is an integral part of angiogram assessment, particularly of macular diseases. Similarly the clinical descriptions of the various retinal diseases are short and not always accurate. The section on the development of neovascularisation in aging macular degeneration is muddling and the chapter on diabetic retinopathy perfunctory. Some conditions - for example, macroaneurysm, retinal vasculitis, and some of the retinal pigment epitheliopathies - are not described at all.

One has the impression that the book has been written around an excellent set of colour photographs with corresponding fluorescein angiograms. Overall this has generated an excellent primer for readers wanting an introduction to the subject of fluorescein angiography. Since the initial texts published when angiography was a relatively new subject there have been few textbooks on it, and therefore the present volume is to be welcomed. A large amount of angiographic information lies scattered in the ophthalmic literature. This book is useful as an early introduction to the subject in that it draws together the appearances of common retinal diseases. In contrast to the publisher's notes on the cover it is unlikely that the book will be of much value to those retinal specialists looking for more detailed or diverse information.

R H B GREY

Atlas of Ocular Motility. By Leonard B Nelson, Robert A Catalano. Pp 228. $£ 60.75$. Saunders: London, 1989.

The authors have produced a very comprehensive manual on strabismus. They begin with a detailed account of the anatomy and physiology of the extraocular muscles. There is a thorough description of the tests for visual acuity and binocular function, with an explanation of the underlying physiological basis of Panum's fusional space and stereovision. The standard orthoptic tests are covered in some detail. As a result less than half the text comprises photographs and description of abnormalities of ocular motility. However, in my view the balance is well struck, and the lucid and highly diagrammatic introduction to assessment of motility disorders is followed by well chosen illustrations of the more common conditions, with succinct text. This is an excellent book, which should prove useful as an introductory text for the fellowship candidate and as an approachable reference book.

R A HARRAD

$*_{*}^{*}$ All titles reviewed here are available from the BMJ Bookshop, PO Box 295, London WC1H 9TE. Prices include postage in the UK and for members of the British Forces Overseas, but overseas customers should add $£ 2$ per item for postage and packing. Payment can be made by cheque in sterling drawn on a UK bank, or by credit card (MASTERCARD, VISA or AMERICAN EXPRESS), stating card number, expiry date and your full name.

\section{NOTE}

\section{Volunteer Eye-Surgeons' Association}

On 11-12 October the Pre-AAO 1991 2nd International Meeting of the Volunteer Eye Surgeons' Association and any and all Third World 'Free Sight-Restoration' Groups will be held at Anaheim, California. For information, call or write: Robert C Welsh MD, 1600 Onaway Drive, Miami, FL 33133, USA (305) 856-1375 (nights). 